\title{
Cassandra Rios e a lésbica genuína em Eu sou uma lésbica (1980)
}

\author{
CAROLINA CASTELLANOS GONELLA \\ Dickinson College
}

\begin{abstract}
In this article, I analyze the novel, Eu sou uma lésbica (1980), by Brazilian author Cassandra Rios (1932-2002). I examine how Rios's text discusses the lesbianism and sexuality of Flávia, the protagonist of the novel, as well as the sexual and love relationship that the seven-year-old Flávia has with an adult woman. The work of authors such as Judith Butler, Marilyn R. Farwell, Teresa De Lauretis, Adrianne Rich, Gayle Rubin, and Jeffrey Weeks informs my theoretical framework. I propose that the novel presents Flávia's sexuality as natural and genuine in order to challenge traditional discourses surrounding lesbianism and children's sexuality. While the representation of lesbian sexuality in children is transgressive and empowering, as it establishes same-sex desire among women as natural and dating back to infancy, I contend however that the novel's treatment of adult lesbian sexuality perpetuates traditional corporal, racial, and class hierarchies.
\end{abstract}

Keywords: Brazil, lesbianism, children's sexuality, lesbian literature

O artigo "Thinking Sex: Notes for a Radical Theory of the Politics of Sexuality," de Gayle Rubin, além de se converter em um dos textos fundadores dos estudos queer, causou (e ainda causa) uma grande comoção, uma vez que Rubin propõe que sexualidades vistas como marginais e ilegais devem ser valorizadas por vivermos em sociedades que naturalizaram a heterossexualidade como o único desejo possível. A mentalidade que entende o gênero, a orientação sexual e os desejos como binários, cisgêneros e heteronormativos precisa ser repensada. Em 1984, o ano em que o artigo de Rubin foi publicado, a escritora brasileira 
Cassandra Rios (1932-2002) já tinha se consolidado como uma autora que tratava temáticas sobre sexualidades que a sociedade brasileira devia e ainda deve repensar. Desde seu primeiro romance, A volúpia do pecado de 1948, e nos seus mais de cinquenta romances publicados, Cassandra construiu personagens com sexualidades diversas que refletem a complexa natureza humana. ${ }^{1}$ Elas podem ser tanto benevolentes, trabalhadoras, amáveis, quanto assassinas e maldosas, mas ao contrário de outros textos sobre sexualidades que não são normativas na literatura brasileira que precede e que é contemporânea de Cassandra, de acordo com Rick Santos, usualmente as personagens cassandrianas são mostradas de forma positiva ("O mito" 258).

Um dos últimos romances publicados pela autora, Eu sou uma lésbica (1980), discute a lesbianidade e a sexualidade infantil. Analiso o texto com o propósito de resgatar uma autora que discute temas que continuam sendo importantes para a afirmação da comunidade LGBTQIA na literatura brasileira. Este romance é diferente de outros romances anteriores de Cassandra, como A tara (1967?), Uma mulher diferente (1968), Tessa, a gata (1968), Copacabana posto seis: a madrasta (1972), As traças (1975?) e Anastácia (1977), ${ }^{2}$ porque apresenta sexualidades marginalizadas como naturais, conscientes e admiráveis sem cair em tragédias, ao passo que desenvolve uma personagem principal complexa que constantemente se autoafirma. ${ }^{3}$ Enquanto que nos outros romances mencionados as personagens lésbicas, bissexuais ou que gostam de mulheres são criminosas ou têm finais trágicos.

O contexto de Eu sou uma lésbica marca uma das principais diferenças com os outros romances porque, ao ser publicado como folhetim na revista Status em 1980, o Brasil estava começando o processo de redemocratização. A partir de abril de 1964 um regime militar de direita se instaurou no Brasil, período que ficou marcado por uma intensa repressão. Durante os mais de vinte anos dessa ditadura militar, o país sofreu grandes transformações no que diz respeito à

\footnotetext{
${ }^{1}$ Não existe um acordo sobre o número exato de textos publicados por Cassandra. Mariana Souza Paim considera que são aproximadamente 52 romances (29), enquanto Rick Santos indica que foram mais de quarenta ("O mito" 258).

${ }^{2}$ Devido às várias republicações e à falta de pesquisa, é difícil determinar com exatidão o ano de publicação de cada romance.

${ }^{3}$ Outros romances com final feliz são Eudemônia (1949), censurado em 1954 (Londero 39-40; 106), e Macária (1973), mas não desenvolvem a complexidade de Eu sou uma lésbica e foram publicados em outros contextos.
} 
censura. Porém, a repressão chegou ao ápice com a promulgação do AI-5, o ato institucional número cinco, em dezembro de 1968. Tal ato fechou o congresso, passou os poderes legislativo e judiciário para o então presidente, instaurou a censura, proibiu encontros políticos e cassou direitos civis, incluindo o habeas corpus.

No âmbito das artes, a censura alcançou pontos extremos e muitos artistas foram forçados ao exílio. Embora este não tenha sido o caso de Cassandra Rios, sua obra foi continuamente censurada, além de ter prestado depoimentos em delegacias em diversas ocasiões (Korich, Cassandra). Se a sua obra já tinha sido censurada nos anos cinquenta (Korich, Cassandra), muitos de seus romances seriam também censurados de forma sistemática durante a ditadura da segunda metade do século vinte (Londero 24). Segundo Deonísio da Silva, o período compreendido entre 1974 e 1978 ilustra a dimensão de tal repressão, já que mais de quinhentas obras foram banidas neste período (15), sendo que quinze eram romances de Cassandra (295-308). ${ }^{4}$ Da Silva explica que os temas relacionados à sexualidade em geral eram banidos, mas a censura também tinha gênero porque Cassandra e Adelaide Carraro estiveram entre as mais censuradas (17). Cassandra em si sabia que era censurada por tratar temas relacionados com sexualidades que não são normativas e (principalmente) por ser uma mulher brasileira falando de sexualidade (Korich, Cassandra).

Apesar da censura, Cassandra foi uma das autoras de maior sucesso, já que vendeu mais de um milhão de cópias (Piovesan e Fontoura Jr. 2413). Ela é também uma das autoras mais esquecidas no Brasil; só algumas de suas obras foram republicadas nos últimos anos, em parte pelo trabalho de Santos, enquanto que grande parte da crítica literária ainda as ignora. Em maior parte, os críticos rejeitam os textos da autora por tratarem temas considerados tabu durante as décadas de 50, 60 e 70. Além disso, segundo Adriane Piovezan, os leitores da literatura lésbica contemporânea costumam rejeitar Cassandra pelo seu moralismo e desenvolvimento de personagens estereotipadas (Amor 13). Para Piovezan, esses críticos não veem a complexidade desenvolvida em suas obras (11-20). Devido ao grande número de romances publicados, é difícil ter uma compreensão abrangente da escrita de Cassandra.

\footnotetext{
${ }^{4}$ Segundo Paim, foram 36 romances cassandrianos proibidos (30), enquanto Sandra Reimão indica $18(40)$.
} 
Uma outra questão que divide a crítica literária sobre o valor da obra cassandriana é a linguagem. Enquanto alguns acham que é discriminatória e reproduz estereótipos sobre a comunidade LGBTQIA, outros discordam. Piovezan aponta que se trata de uma linguagem acessível que explica temas escandalizadores e que usa termos e preconceitos da época com o propósito de engajar leitores ("Sou uma"). Além disso, críticxs e editorxs engajadxs com a comunidade LGBTQIA não se interessam em republicar a obra, devido ao fato de que muitas personagens cassandrianas têm finais tristes, ou são destrutivas e autodestrutivas, uma vez que podem se suicidar, como em Copacabana posto seis, ou matar, como em Anastácia. No documentário da diretora Hanna Korich, Cassandra Rios, a safo de perdizes, Laura Bacellar sugere que publicar obras de autores que celebram sexualidades marginalizadas e que têm um final feliz é uma estratégia política positiva para a comunidade LGBTQIA.

Ainda com finais trágicos, a obra de Cassandra insere-se na narrativa lésbica ficcional, cuja definição já foi alvo de muitos debates nos EUA. Algumas críticas determinam que deve incluir vários fatores como ter personagens lésbicas centrais, enfatizar o amor e a paixão entre mulheres, expressar as visões e desejos da comunidade lésbica e ser feita por escritoras lésbicas assumidas, enquanto que outras salientam a importância da leitura e da leitora (Zimmerman 14-16; Farwell 11-16). A obra de Cassandra apresenta estas características e leitoras, assim como estabelece contextos e vozes narrativas similares. De fato, entre 1970 e 1990, a ficção lésbica nos EUA e na Europa era comparada com romances populares que tinham pouca profundidade (Farwell 5), o que aconteceu também com os textos cassandrianos (Santos, "Cassandra" 19). Nestas décadas, Marilyn R. Farwell identifica o "sujeito lésbico metafórico" como ferramenta poderosa para questionar o binarismo e a armadilha da homossexualidade e homossocialidade como exclusivamente masculinas (17). Além disso, este sujeito possui gestos utópicos e desconstrutores importantes (Farwell 17-18). No contexto brasileiro, Cristina Ferreira-Pinto nota que as escritoras brasileiras desenvolveram uma crítica feminista da "master narrative," sobretudo com respeito à representação do corpo, sexualidade e desejo das mulheres (3). Embora Ferreira-Pinto e Farwell não analisem a obra de Cassandra, ela insere-se nesta crítica. Flávia, por exemplo, a narradora e protagonista de Eu sou uma lésbica, representa esse sujeito lésbico metafórico, devido a que quebra estereótipos sobre a lesbianidade e mostra sua sexualidade de forma utópica. 
Republicado em 2006, Eu sou uma lésbica possui um tom positivo, esperançoso e autoafirmativo que, ainda criticando a sociedade, reflete um contexto que repensava liberdades, porque o AI-5 havia sido removido em 1978, a anistia geral havia acontecido em 1979 e já havia se iniciado o processo de redemocratização. A narradora Flávia explica que quando tinha sete anos se apaixonou pela vizinha, Kênia, que na época tinha 26 e estava casada. Flávia consegue brincar com Kênia e as duas terminam envolvidas numa relação de paixão e desejo. Porém, Kênia vai embora da cidade. Flávia continua sua vida como lésbica "genuína," e relata seus casos e desapontamentos com outras duas mulheres. Quinze anos depois, Kênia volta viúva e Flávia lembra que antes de Kênia ir embora, ela tinha colocado vidro amassado na sopa de Eduardo, o marido de Kênia. Elas finalmente se encontram, reconhecem o crime feito pela criança e retomam seu relacionamento.

Este romance é escandalizador e pornográfico, característica típica da narrativa cassandriana, porque relata um caso (que parece) de estupro e de pedofilia entre mulheres, assim como um assassinato. Considero o romance pornográfico porque trata de temas e usa palavras e imagens que explicitam o ato sexual e que são considerados obscenos ou provocativos no seu contexto (Sullivan e McKee 13), mas com a palavra "pornografia" não condeno a obra. Tampouco considero que o tom pornográfico desvirtue a luta feminista. ${ }^{5}$ De fato, este tom contribui a desenvolver um manifesto lésbico na medida em que justifica e valoriza a sexualidade infantil e a lesbianidade. Por pedofilia me refiro ao desejo de umx adultx por umx menor de idade (Weeks 127-29) e também ao relacionamento não consensual entre umx adultx e umx menor, já que se considera que estx últimx é inaptx a aceitar tal relacionamento. Enquanto muitas sociedades estabelecem idades mínimas diferentes para penalizar a pedofilia, $E u$ sou uma lésbica questiona a ideia de uma criança não poder dar seu consentimento, representando somente a parte sexualmente explorada. De acordo com Jeffrey Weeks, o entendimento convencional sobre o consenso assume que as atividades sexuais devem estar baseadas "on the free will of autonomous agents able to decide for themselves whether, or not, to engage in that particular practice" (32). O romance se aproxima desta definição, já que o relacionamento

\footnotetext{
${ }^{5}$ A discussão atual sobre pornografia é diferente da dos anos 80 e 90 sobre a objetificação e exploração do corpo feminino (Williams 2).
} 
com Kênia se concentra em temas relacionados com a agência, agenda e procedimentos consensuais da criança.

No romance, a afirmação positiva/utópica da sexualidade está baseada principalmente na naturalidade e genuinidade. Entendo a naturalidade como um discurso que mostra que orientações marginalizadas não são resultado de discursos artificiais ou influência de outras pessoas. Este discurso se relaciona com o "lesbian self," identificado por Bonnie Zimmerman, já que para diversificar a construção deste sujeito lésbico as autoras devem expulsar a convicção (internalizada) de que a lesbianidade não é natural (41). Pode-se ver, portanto, que o discurso natural é essencial na autoafirmação de Flávia. Além de ser uma ferramenta sociopolítica importante no romance, a ênfase no natural também é utópica porque Flávia não enfrenta problemas. Esta afirmação ideal se fundamenta na ideia de a lesbianidade ser "genuína," o que significa que ela não é produto de traumas, rebeldia ou modas passageiras. Ela está presente desde o nascimento, é consciente desde a infância e faz parte da própria natureza humana e do destino de uma pessoa. Por isso, proponho como hipótese geral neste artigo que o romance apresenta a sexualidade lésbica como genuína e natural tanto na infância quanto na maturidade. Porém, enquanto a sexualidade lésbica infantil é construída como transgressora, porque convida a repensar os discursos tradicionais sobre a pedofilia, sugiro que a sexualidade lésbica adulta é menos transgressora, já que reproduz normas tradicionais sobre a aparência, o corpo, a raça e a classe.

\section{A sexualidade desde a infância}

Para examinar como o romance faz repensar discursos tradicionais sobre a sexualidade infantil, nesta seção analiso como a sexualidade se apresenta como natural, a partir de referências à normalidade, honestidade, natureza humana, $\mathrm{o}$ reino vegetal e o destino. Proponho que além de apresentar a lesbianidade e a sexualidade infantil como válidas e naturais, o romance as justifica ainda mais ao baseá-las na agência de uma criança de sete anos. Desta forma, o discurso afirmativo de Flávia sobre sua sexualidade e orientação derruba teorias da psicanálise tradicional, já que este campo de estudo explica que sexualidades que não são normativas são anormais, porque representam desvios dos complexos de Édipo, Electra ou da ansiedade de castração. Porém, como explica Graciela 
Haydée Barbero, as homossexualidades se consideraram doenças, perversões, desvios e até sintomas, porque eram confundidas com discursos de cunho moral (69-70). Deste modo, desvalorizava-se tudo que saísse dos padrões morais de uma determinada sociedade.

Eu sou uma lésbica também rejeita os discursos da sexologia e imagens negativas das lésbicas na literatura, como a mulher fatal e a ninfomaníaca. Devido a que Flávia afirma que sabia muito de sexo, sobre tudo de sexologia (88), é evidente que há referências a este campo no romance. O livro Psychopathia sexualis (1886), do psiquiatra Richard von Krafft-Ebing, que, segundo Harry Oosterhuis, converteu-se em referência central em círculos médicos e na vida diária (46), define a homossexualidade como tara ou degeneração e diferencia a sexualidade patológica da saudável (Oosterhuis 48, 64-65). Este livro, portanto, contribuiu para estabelecer a homossexualidade como anormalidade ainda quando outros médicos discordassem. De acordo com Elizabeth Roudinesco, Sigmund Freud se recusou a qualificar a homossexualidade como tara ou anomalia, mas outros psicanalistas não só o consideraram, mas também insistiram que era crime (50-51). Apesar destas diferenças no campo, historicamente a homossexualidade sofreu patologização, deixando de ser considerada doença pela Organização Mundial da Saúde somente em 1990.

Com respeito às imagens negativas sobre a lesbianidade, Farwell nota que o desenvolvimento do sujeito lésbico metafórico é uma resposta às construções negativas das mulheres lésbicas dos escritores do século dezenove (16). Como explica, "From Baudelaire's notorious description of the 'Femmes damnées' as a representation of modernism to Richard von Krafft-Ebbing's paradigm of the lesbian subject's journey into nonfeminine monstrosity, the lesbian has represented a female figure of disruption, horror, and bodily grotesqueness" (1617). Para Linnea A. Stenson estas imagens negativas podem ser retomadas e revisitadas com o propósito de refletir melhor como as lésbicas se percebem a si mesmas no seu contexto (476). Na narrativa cassandriana, a lesbofobia é repensada para promover uma sexualidade utópica durante um governo de intensa repressão.

Com Flávia, o romance se aproxima daquilo que Adrienne Rich, em "Compulsory Heterosexuality and Lesbian Existence," chama de existência lésbica. Segundo Rich, a existência lésbica constitui os traços e conhecimento 
das mulheres que fizeram de mulheres a primeira eleição erótica e emocional (41). Essa existência é evidente quando Flávia se explica a si mesma: "O que eu quero afirmar é que em mim tudo é natural, consciente, vivo, espontâneo. Sou definida, autêntica, honesta, mas um tanto covarde, ainda" (39). É vital que Flávia assegure que, como a natureza, ela está viva, é consciente e age de forma franca. Dessa forma, desejar mulheres não é nem artificial nem falso e as mesmas mulheres são autoconscientes de seus desejos.

A existência lésbica também é visível com o discurso da naturalidade, como quando Flávia diz: "Segui e cheguei a um caminho de vida preestabelecido pela minha própria natureza" (34). A afirmação enfatiza que não ser lésbica seria ir contra a própria natureza. A identidade de Flávia antecede qualquer imposição social, de modo que negar sua orientação e desejos é agir com violência antinatural. Considerando que desde finais do século 19 o homossexual era visto como invertido (Ellis 7, 250-51), o romance ataca esta ideia porque Flávia não possui uma sexualidade invertida. Além disso, ser fiel à própria natureza tem outras implicações, como quando Flávia diz: "Estava predestinado que eu jamais conseguiria amar um homem, que somente outra mulher poderia fazer-me vibrar, excitar-me e fazer pulsar mais forte o meu coração" (37). A palavra "predestinado" afirma a normalidade e faz uma referência à (mãe) natureza ou à mesma libido, de modo que se reitera que a lesbianidade não é inversão.

A conexão entre a lesbianidade e o natural se desenvolve ainda mais no romance porque Flávia se considera um "criptandro." Como ela não gosta da palavra lésbica (61), identifica-se como criptandro várias vezes $(37,61,72,75$, 142). ${ }^{6}$ Esta palavra vem do grego kruptos, para oculto, e aner, para andros, que significa "homem" no sentido biológico e que na botânica refere-se aos vegetais que não possuem órgãos masculinos aparentes. Ao se associar com esta planta, Flávia confirma o discurso do natural, porque a sexualidade dela está presente até no reino vegetal: "Isso eu era, uma tenra plantinha que crescia, um criptandro" (37). Não há nada artificial em Flávia no sentido em que ser planta é ser parte da natureza. Esta ênfase esclarece que a orientação de Flávia é "verdadeira," de modo que o romance discorda do conceito de "pseudo-homossexualidade" do sexólogo Havelock Ellis. A pseudo-homossexualidade para Ellis não é congênita, porque é simulada, falsa ou influenciada por diversos fatores (7).

\footnotetext{
${ }^{6}$ Segundo Piovezan, Cassandra discutiu frequentemente o uso do termo "lésbica" (Amor 30).
} 
Além de congênita, natural, genuína e honesta, a orientação de Flávia está presente na infância: "A sensualidade nasce com a vida, e no modo como eu olhava e admirava os pés de dona Kênia estava a primeira manifestação de sexualidade" (11). Nesta citação, a sexualidade infantil não é nem desvio nem produto de traumas, problemas ou complexos que não foram resolvidos. De fato, Flávia explica que jamais teve problemas nem rivalidade com os irmãos (33), como se atacasse o complexo de Electra ou a inveja do pênis. Ela até diz que "[n]ão há nenhum complexo de Édipo entre ser heterossexual e homossexual" (38), de modo que, como sujeito lésbico, ataca estereótipos sobre a orientação sexual.

Uma questão específica da psicanálise que o romance desvirtua é o fetiche, porque os pés de Kênia são um fetiche para Flávia, que usa uma sandália de Kênia para se masturbar. Por fetiche, refiro-me à estimulação sexual que se consegue de objetos que não são sexuais (Weeks 57). Freud estabelece o fetiche como relacionado com o complexo de Édipo, já que ao negar a castração da mãe, o desejo do sujeito é deslocado para outros objetos ou partes do corpo. Por isso, Freud considera que as mulheres não desenvolviam fetiches (De Lauretis 22332; Weeks 57). Porém, feministas derrubam essa análise quando mostram o fetiche como parte central da sexualidade lésbica (De Lauretis 227-32; Weeks 57). O romance cassandriano desvirtua a teoria freudiana ao apresentar como vital o fetiche para Flávia lembrar e desejar Kênia. ${ }^{7}$ Como Piovezan nota, as obras de Cassandra defendem o prazer da mulher em uma sociedade onde o prazer era unicamente dos homens (Amor 12). O romance valoriza, portanto, a sexualidade de todas as mulheres.

A valorização específica da sexualidade infantil possui outras conotações porque Flávia tem sete anos: "Mas os fatos primordiais, os acontecimentos que estabeleceram a genuinidade do meu modo de ser-ou mais acertadamente, a genuinidade do que eu era como ser humano, participando da sociedaderealmente se concentraram todos na primeira infância, nos meus coloridos e fantasiosos sete anos de idade" (34). Repete-se o tema da genuinidade, mas com a palavra "estabelecer" os sete anos se convertem em um momento de ratificação da orientação da criança. No plano simbólico, o número sete representa a

\footnotetext{
${ }^{7}$ Flávia considera que sua lesbianidade é natural e que a anomalia é seu fetiche (62). Porém, nesse momento do romance ela ainda não entende a importância da sandália.
} 
totalidade, a consciência, o fim e o começo dos ciclos, de modo que amar desde os sete anos marca a consciência sobre a própria sexualidade e começa a vida sexual. Além disso, considerando que as amigas da mãe se reúnem em casa, Flávia começa a participar da sociedade interessada nos pés de Kênia e desenvolvendo seus desejos, de modo que sua sexualidade é pública e social, não somente privada ou individual.

O foco na naturalidade também está relacionado com a estratégia da naturalização. Os atos que a sociedade vê como escandalosos, o romance os desconstrói ao ponto de banalizá-los, de modo que os naturaliza. David William Foster nota que, junto com outros escritores latino-americanos, em sua obra Cassandra desenvolveu um discurso sexual que naturalizou o proibido e o tabu (142). ${ }^{8}$ Se a sociedade hegemônica faz com que a heterossexualidade seja percebida como natural, Eu sou uma lésbica naturaliza atos que tradicionalmente se veem de forma negativa ou que são rejeitados. Para Krafft-Ebing, o comportamento sexual que não tinha a meta da reprodução era perversão (Oosterhuis 47), e a sexualidade infantil, assim como a masturbação, eram elementos importantes das causas da perversão (57). O romance, portanto, é transgressor ao desnaturalizar a artificialidade da heteronormatividade e salientar a validez da sexualidade infantil.

Esta desnaturalização aparece desde o início do romance quando, estando sob a mesa, Flávia lambe a perna de Kênia: “Afinal, o que poderia significar uma lambida na perna de uma linda mulher perfumosa, dada por uma menina de sete anos?" (13). Ao criar a pergunta e não respondê-la, separa-se o desejo do ato feito pela criança e explicam-se os dois de forma corriqueira. Com a pergunta sobre o que poderia significar a lambida, a ação de lamber vira um ato como qualquer outro e deixa de ser erótica mesmo sendo-a. Dessa forma, o texto não relativiza as ações de Flávia, mas procura reduzir o (possível) escândalo na leitora ao apresentar o ato da menina como insignificante. Além disso, separar a lambida de uma atividade erótica e sexual, isola o evento de qualquer valoração negativa tradicional sobre a sexualidade infantil, enquanto se espera tolerância da leitora.

Santos explica que na ficção de Cassandra, as leitoras podem reconhecer traços virtuosos em personagens gays ("Cassandra" 22). Considerando esta ideia,

\footnotetext{
${ }^{8}$ Santos explica que a obra desfamiliarizou o familiar e reinscreveu significados que evitaram a censura ("Cassandra" 25).
} 
pode-se observar que com a pergunta sobre o significado da lambida, o sujeito lésbico introduz um marco de referência para a leitora que impossibilita a valorização negativa tradicional. Se as crianças são inocentes e uma lambida é só uma lambida, não tem escândalo nenhum. Até o título do livro leva as leitoras a se identificarem com o sujeito lésbico metafórico e fazerem parte do mundo dela. Esta mesma técnica de naturalização é visível quando Flávia chupa os peitos de Kênia pela primeira vez. Ela diz "Isso tudo, entretanto, não oferecia o menor caráter de obscenidade. Nada de repugnante e de proibido" (30). O comentário procura reiterar a falta de escândalo. Linda Williams explica que a raiz latina da palavra "obscenidade" significa aquilo que deve estar fora da vista do público, quer dizer, fora de cena (3), e o romance usa justamente essa palavra para subverter a regra. Emprega-se "obscenidade" para mostrar que chupar um peito não deve ser oculto, porque há que reconhecer a sexualidade da menina de sete anos. Igualmente, ao acrescentar que o ato não é nem "repugnante" nem "proibido," esclarece-se que não se trata nem de abuso infantil, nem de estupro.

Dessa forma, o romance trata a pedofilia de forma transgressiva porque a menina é quem deseja a relação, inicia o relacionamento e tem agência e agenda. Foram suas iniciativas e criatividade que a fizeram se envolver com uma adulta. Na descrição da primeira vez que chupa os seios de Kênia, Flávia explica que "dei uma lambidinha seca e rápida no seu queixo, segurei o seu rosto com as minhas mãozinhas inocentes e o lambi; desci para o pescoço e, antes que ela tivesse tempo de interceptar o meu gesto ou entender o que estava acontecendo, minha boca já arrepanhara o bico do seu seio" (30). A menina é mais rápida, esperta e inteligente do que a adulta, de modo que o romance subverte a visão tradicional a respeito do jogo de poderes em uma relação sexual. Tipicamente umx adultx manipula a situação, como no caso da mulher fatal. Além disso, o romance não mostra que a vítima esteja justificando a sua própria exploração; mostra que as mulheres, e particularmente as lésbicas, conhecem sua sexualidade desde crianças. Considerando também que a narradora não é a criança de sete anos, a narração é feita pela adulta que revisita os eventos de sua infância. Não se trata de uma manipulação narrativa que diminui a responsabilidade de Kênia, mas de um discurso que Flávia constrói para se explicar e justificar. O romance, portanto, resgata a autonomia da criança lésbica e desmente o estudo de Ellis que argumentava que a homossexualidade nos jovens se devia a um impulso sexual indiferenciado (103). O sujeito lésbico metafórico adulto entrelaça eventos de 
seu passado para se explicar como mulher que gosta de mulheres desde os sete anos e, desse modo, justificar sua orientação e identidade em uma sociedade heteronormativa.

Não procuro mostrar que o romance acerta com o tipo de sexualidade que propõe, mas salientar, que como narração lésbica ficcional, Eu sou uma lésbica reivindica sexualidades marginalizadas ao tempo que procura educar suas leitoras. Elizabeth English observa que "[t]his connection between fantasy, lesbian subjectivity and sexuality has become significantly more explicit in recent decades, with lesbian writers using fantasy to openly explore sexual themes, particularly in science fiction" (29). A fantasia no romance cassandriano permite esta exploração temática, mas por fantasia não me refiro ao gênero da literatura fantástica, mas a que o texto apresenta um tema fantasioso e ficcionaluma relação ilícita e proibida. A pedofilia no romance não se trata da exploração do corpo da criança por parte de umx adultx. O foco se dá à narração da menina e o prazer que esta tem ao acariciar a mulher adulta.

A sexualidade infantil ainda é vista por setores de muitas sociedades como antinatural e manipulável, mas Jeffrey Weeks explica que, "[1]egitimacy for sexual activity comes not from the law or an age of consent, but from a sense that it should happen only when the young individual is ready, that it is a product of agency, choice and control mediated by time" (24). No romance, a agência e orientação de Flávia determinam o relacionamento com Kênia. Esta última aparece mais como o corpo aproveitado sexualmente, porque ela é uma mulher linda, boa, ingênua que encontra em Flávia o prazer que seu esposo, enfermo terminal de câncer, não lhe podia dar. A descrição e o prazer de Kênia são diminuídos e até certo ponto simplificados, já que a narradora adulta dá prioridade à sua própria história, à da mulher que sabe que ama outras mulheres desde criança. O moralismo ou críticas vêm da sociedade que não aceita as relações entre mulheres, assim como a autonomia sexual das meninas.

Deve-se considerar também, com respeito à descrição da pedofilia, que como o corpo sexualizado no romance é o da adulta, há uma grande diferença com textos como O caderno rosa de Lori Lamby (1990) de Hilda Hist. Nesta obra, as descrições da menina de oito anos, mesmo que tinham sido inventadas por ela, são sobre como homens tocam e lambem o corpo dela. A obra de Cassandra, então, naturaliza um tema tabu para salientar o prazer natural das mulheres, o qual não é produto da exploração de adultxs ou da imaginação infantil. 


\section{A lésbica adulta}

Depois de ter analisado a sexualidade na infância, nesta seção analiso a lesbianidade na adulta e foco em três estereótipos - o ódio aos homens, a ninfomania e a masculinidade — e como aparecem na interação de Flávia adulta com outras personagens. Proponho que, ainda minando discursos tradicionais e educando leitoras, o texto apresenta um ideal de mulher lésbica baseado em convenções sociais, já que Flávia é de classe média alta, branca, magra e bonita.

$\mathrm{O}$ ódio aos homens é um dos estereótipos sobre as lésbicas que o romance apresenta quando Flávia adulta interage com Núcia e Fábio. Tradicionalmente, uma das explicações fornecidas para explicar a lesbianidade tem sido o ódio aos homens, como com as amazonas (Rupp 6). Essa "teoria" busca radicalizar a sociedade com o objetivo de discriminar mulheres lésbicas e obrigá-las à heterossexualidade. Núcia explica a Fábio que Flávia não gosta dele, porque tem nojo de homem (80). Flávia não responde, mas pensa que "[n]ão era verdade o que Núcia estava dizendo, que eu odiava os homens. Meu pai e meu irmão eram homens e eu os adorava" (80). Dessa forma, a leitora do romance é informada que gostar de mulheres não é odiar ou ter nojo dos homens. Flávia não se precisa explicar ante Fábio, porque o importante é educar as leitoras do texto.

Um outro estereótipo que surge entre Flávia, Núcia e Fábio é que as lésbicas são mulheres viciadas em sexo. ${ }^{9}$ Para Carol Groneman, o discurso da ninfomania constrói uma sexualidade feminina fora de controle, seja do controle familiar, medicinal, ou das leis naturais (342). Neste sentido, as mulheres lésbicas se opõem ao papel da mulher como esposa e mãe. Além disso, ao fim do século 19 as descrições dos médicos sobre as mulheres lésbicas eram muito parecidas com as das ninfomaníacas (355). No romance, Fábio evidencia esta conexão com a ninfomania; referindo-se à lesbianidade, ele diz, "[a]cho que isso é coisa de mulheres ardentes, solitárias, celibatárias, mulheres que se preocupam com a emancipação, mas que agem de modo errado" (84). Ele relaciona a mulher ardente com a emancipação das mulheres, de modo que, no seu discurso, a luta pelos direitos das mulheres e o trato igualitário na sociedade não se originam em injustiças políticas e sociais. Despolitiza-se, assim, a emancipação ao reduzi-la a uma sexualidade desenfreada em que a mulher de fogo nas veias não

\footnotetext{
${ }^{9}$ Este estereótipo aparece em outros romances de Cassandra, como Anastácia e Tessa, a gata.
} 
necessariamente luta contra a sociedade patriarcal pelos seus direitos. A citação também é lesbofóbica, porque evita associar a emancipação das mulheres com a luta da comunidade lésbica e LGBTQIA.

O estereótipo da ninfomaníaca também desvaloriza a sexualidade feminina, como quando Fábio diz: " $E$ a mulher ardente, a que tem fogo nas veias, a que não aceita esses preceitos, que a limitam e cerceiam a sua liberdade, acaba procurando a sua amiguinha [...] a que está para essas coisas" (85). Na citação, as mulheres que gostam de sexo são anormais e buscam uma outra mulher para fazer sexo, de modo que a lesbianidade somente existe na urgência sexual, porque o corpo de uma mulher simplesmente substitui o corpo de um homem. Porém, esta desvalorização da sexualidade lésbica mostra que as lésbicas escapam a heteronormatividade, devido a que não cumprem o papel de esposa e mãe. Como Ferreira-Pinto nota, o desejo lésbico nas obras das escritoras brasileiras é uma dimensão importante da sexualidade feminina ao passo que questiona o controle social do corpo da mulher (120). O discurso de Fábio explica a lésbica como falsa, porque o desejo e a atração por uma outra mulher não existem. A mulher não é valorizada como corpo que deseja e é desejado por uma outra mulher, mas Flávia, como sujeito lésbico metafórico, justamente contradiz essa desvalorização ao passo que reclama o controle de seu próprio corpo e desejos. Para desvalorizar ainda mais a sexualidade feminina, o estereótipo da ninfomaníaca resgata a presença do homem. Fábio diz, "[v]ocê tem vergonha e medo de homem. Está amarrada a preconceitos impostos por uma educação rígida e errada, que deformou os seus desejos. O homem virou tabu para você" (89). Segundo ele, o homem ficou tão longe das mulheres que o único corpo utilizável para o prazer sexual era o de uma outra mulher. Dessa forma, elementos ausentes na sexualidade lésbica como o homem e o falo, que simbolizam o poder masculino tradicional, viram o centro. Se o romance apresenta o discurso de Fábio, também lhe fornece ferramentas a leitora para que compreenda porquê Flávia não age dessa forma, com o que continua educando no questionamento dos discursos da heteronormatividade.

Judith Butler explica que a heteronormatividade para poder continuar sendo a ideologia imperante, deve ser constantemente reforçada para evitar ameaças que a desestabilizem (Gender 185). Essa compulsividade em ser sempre confirmada mostra o caráter artificial do sistema heteronormativo. Se fosse natural, a heteronormatividade não precisaria limitar performances, desejos e 
orientações. Eu sou uma lésbica quebra com essa compulsividade quando mostra que atos naturais são vistos de maneira negativa e, quando salienta contradições no discurso de Fábio. Por exemplo, ele reproduz a ideia de "tara" de KrafftEbbing e a relaciona com a ninfomania, quando diz para Flávia: "Núcia apenas usou você sexualmente, para satisfazer suas taras. Ela não passa de uma ninfômana" (88). ${ }^{10}$ Se a "tara" indica uma degeneração permanente e um defeito hereditário de tipo moral ou físico, este discurso se quebra quando Fábio diz que pode ser superado. Flávia diz sobre Fábio: "Ele falava, fazia discurso, verdadeiros libelos contra o lesbianismo. Tinha certeza de que eu não era nada disso. Se eu quisesse, poderia me libertar do "vício"” (86). Na citação, por um lado, a mulher lésbica é um problema e, por outro, ela não é um perigo já que pode se reinserir na sociedade. Essa incoerência, entre o sério problema ser somente um vício, mostra como a heteronormatividade tenta se reforçar.

A incoerência também indica que a vontade da mulher pode acabar com o problema. Flávia explica que Fábio estava: "Tentando me convencer que eu não era o que era, que aquilo de lésbica era desvio sexual, que era só querer e a mulher se reintegrava ao certo e melhor" (87). A responsabilidade fica na mulher, porque se ela não quiser e não parar o desenfreio sexual, existe um perigo ainda maior: "queria me desviar daquele caminho que conduzia mulheres influenciáveis como eu à perdição, às doenças, à loucura e ao suicídio" (88). Se a mulher não quiser se curar, ela vai se marginalizar e acabar morrendo pelas suas próprias mãos. ${ }^{11}$ Neste discurso, a responsabilidade da sociedade desaparece completamente porque a mulher é quem deve se inserir na sociedade ou ser marginalizada. O discurso não indica que há um "nós" que marginaliza e a leva à morte. A mulher lésbica é completamente desempoderada por um discurso que ironicamente se apresenta como possibilidade de empoderamento. Por isso, os discursos sobre a naturalidade e a genuinidade são tão importantes no romance, já que devem questionar a complexa opressão da lesbofobia e misoginia.

O último estereótipo surge na interação entre Flávia e Núcia e discute a masculinidade, já que se mostra que as mulheres lésbicas não querem necessariamente ser homens. O romance se opõe à ideia de Krafft-Ebing (Oosterhuis 48) e de Ellis (250-51), de que a lésbica é um homem. Este

\footnotetext{
${ }^{10}$ Núcia funciona como um espelho para Flávia, já que nela reconhece seus desejos por outras mulheres, mas também graças a ela percebe que não gosta de homens.

${ }^{11}$ Groneman explica que uma convicção vitoriana é que a ninfomaníaca morre (247).
} 
questionamento é visível com o discurso da naturalidade, que analisei com respeito à inversão, e quando Flávia discute sua indumentária: "Vestidos não eram para mim. E comecei a só andar de calça comprida, camisa, jaquetas, sapatos de solões bem esporte, camisetas, sentindo-me cada vez mais liberta das apreensões e do medo de que os outros descobrissem o que eu era. Mas não era influência de Núcia; eu apenas estava me encontrando melhor dentro da minha indumentária preferida" (65). Conforme Flávia vai encontrando seu estilo e forma de expressão, também vai encontrando comodidade em não reproduzir a feminilidade compulsiva tradicional.

Porém, Núcia quer determinar a imagem de Flávia, já que lhe disse que "precisava cortar os cabelos, usar calças compridas, andar mais esporte. Eu ia ficar uma gracinha, de cair o queixo" (65). Se Flávia usa as camisetas do irmão, ainda não se veste como Núcia quer. Ela, de fato, se aborrece com Núcia quando lhe explica que cortando os cabelos podia parecer com o ator francês Alain Delon: "Eu me irritei. Minha indignação cresceu. Que ela ficasse com o Alain Delon. Preferia continuar parecida comigo mesma ou com a Lauren Bacall, como mamãe achava. Eu era mulher, essencialmente feminina, apenas gostava de mulher. Só isso" (66). Flávia diferencia a identidade de gênero, da performance e da orientação sexual e quebra a ideia tradicional do binarismo entre feminilidade e masculinidade. Porém, sua escolha professa o padrão de beleza europeu tradicional de mulheres brancas que Hollywood converteu em ícones da cultura de massas, como Lauren Bacall.

Com respeito à masculinidade, Flávia também explica que gostava de homens para ter amizade com eles, mas adverte que "[i]mitá-los, nunca!" (66). Ela novamente separa identidade de performance, orientação, desejo e aparência e acrescenta: "[s]entia-me muito bem na minha condição de homossexual, sem precisar caracterizar-me ou realizar performances de machão para agradar as mulheres" (66). O estereótipo que a performance de Flávia derruba é que todas as lésbicas são masculinas (caminhoneiras), porque oferece uma alternativa que também não é a da lésbica feminina (femme). Porém o romance não desenvolve essa performance.

O que é desenvolvido, entretanto, é que Flávia rejeita a masculinidade nas mulheres. Devido à discussão sobre a roupa, Núcia apresenta Flávia a umas amigas. Trata-se de um casal, Bia, que é machona e tem um filho, e Marlene, uma morena feminina e bonita, "mas um tanto vulgar" (67), que segundo Flávia 
obtém dinheiro de um homem velho. Flávia não gosta delas principalmente por duas razões: a primeira é que elas não têm o nível socioeconômico dela (67), e a segunda é porque não gosta da masculinidade de Bia, a quem descreve como "[m]etida a homem, andar de fanfarrão, impostando a voz. [...] As expressões, o modo de andar, tudo nela me enojou," (67). Lúcia Facco e Maria Isabel de Castro Lima explicam que a lesbofobia entre as próprias lésbicas aparece na personagem de Flávia, o que se observa na citação anterior, porque considerar performances de masculinidades como falsas e simples imitações é lesbofóbico. Mariana Souza Paim discute que Cassandra critica a masculinidade nas mulheres lésbicas em $A$ noite tem mais luzes (1968) porque queria se distanciar do estereótipo de lésbica como a mulher que vira homem (78). Paim propõe que essa discussão é uma forma de dar visibilidade às diversas performances das mulheres lésbicas (78). Embora a proposta da crítica seja acertada, o texto reproduz uma visão tradicional da masculinidade, na qual os corpos de mulheres não devem performar masculinidades.

Flávia também rejeita Bia e Marlene porque elas não têm uma sexualidade que Flávia considera apropriada. Flávia representa a lésbica genuína como a mulher cisgênero que jamais teve sexo com homens, mas não por isso os odeia ou quer ser como eles. ${ }^{12}$ Essa genuinidade se distancia do contínuo lésbico proposto por Rich, na medida em que sugere uma pureza sexual. Bia e Marlene são diferentes de Flávia não somente porque escolheram amar mulheres publicamente, mas também porque Bia teve um filho e Marlene explora (e é explorada por) um homem velho. Pode-se ver que o romance não apresenta as comunidades e sexualidades lésbicas como homogêneas ou ideais, já que nem todas as lésbicas agem e pensam da mesma forma. ${ }^{13}$

Porém, ainda expondo conflitos e diferenças, o romance favorece Flávia como a melhor lésbica. Nos EUA, esse fenômeno é conhecido pela classificação do sistema de estrelas, no qual a "estrela platino" é para a mulher cisgênero que jamais fez nada com homens, a "estrela de ouro" é para a mulher cisgênero que beijou só um homem e por aí em diante (Theanglerfish). Além de objetificar as mulheres como metais preciosos e desumanizá-las (Theanglerfish), essa

\footnotetext{
12 Zimmerman analisa os modelos "born-lesbian" e "born-again lesbian" e os relaciona com o contexto em que se usam (52).

${ }^{13}$ No prefácio de Mutreta (1972), Cassandra esclarece que sua escrita mostra complexidades, adversidades e negligências dos "homossexuais" (11).
} 
classificação estabelece hierarquias. Embora Eu sou uma lésbica não utilize esse sistema de estrelas, cria e perpetua hierarquias. A identificação com o criptandro é um claro exemplo de como Flávia marca sua sexualidade de forma diferente, quase única: "São raros os criptandros que florescem entre as lésbicas. São raras as liliáceas neste mundo mal-compreendido que todo mundo quer entender" (75). A citação mostra a lésbica genuína como aquela que não tem relações sexuais com homens e somente está interessada em mulheres, de modo que outras formas de amar, experiências ou identificações são menos válidas.

Flávia é um sujeito lésbico metafórico importante porque questiona discursos tradicionais sobre identidades e sexualidades marginalizadas, mas simplifica a experiência da comunidade LGBTQIA já que não se contestam os privilégios que Flávia tem para poder fazer esse questionamento. Ela é consciente de seus desejos, não os rejeita e não é nem marginalizada ou punida por sua família e sociedade — ela nunca se assume com sua família como lésbica. Igualmente, não se problematiza o fato de que Flávia representa a classe média alta. Como discute Foster, as personagens de Cassandra não têm preocupações econômicas (11920). A lésbica que Flávia encarna é ainda mais específica, considerando que ela é jovem, alta, branca, magra, cisgênero e não tem nem deficiências físicas nem mentais - uma beleza europeia tradicional. Os privilégios físicos, econômicos, familiares e sociais de Flávia invisibilizam as dificuldades que existiam para as mulheres que amavam outras mulheres em 1980. Não se mostram as dificuldades que existem em se identificar e assumir publicamente em uma sociedade lesbofóbica, de modo que relacionar a genuinidade sexual com discursos que se baseiam no privilégio de camadas específicas da sociedade perpetua normas que desempoderam a grande maioria da população LGBTQIA.

\section{Conclusões}

Eu sou uma lésbica trata temas controversos de forma aberta e direta através de um sujeito lésbico metafórico. Mesmo que a lesbianidade seja muito mais aceita e respeitada hoje do que em 1980, ainda se considera que as crianças não têm a capacidade de consentir como adultos. Segundo esses padrões, o romance glorifica o estupro infantil. Porém, lembrando as palavras de Rubin no começo deste artigo, o romance questiona e transgride normas que uma parte da sociedade se recusa a revisar. $O$ texto não justifica o grave problema da 
exploração sexual infantil, mas busca apresentar a complexidade da sexualidade humana na infância e na maioridade. Salientar essa complexidade é uma forma de lutar pelo direito de estabelecer a lesbianidade e outras orientações marginalizadas como naturais desde o nascimento e a infância.

O tom utópico do romance, baseado na naturalidade e genuinidade, contribui para a narrativa lésbica ficcional no Brasil, porque constitui um manifesto lésbico. Se uma das características do gênero do manifesto é ser uma declaração pública que leva uma mensagem política, filosófica, religiosa ou literária (Cuddon 490), o romance apresenta um sujeito lésbico metafórico positivo que mostra e declara que as mulheres lésbicas são autónomas sexualmente. Além disso, comprova que uma criança pode reconhecer seus desejos, agir com base neles e conforme for amadurecendo, aprende sobre a sexualidade e se identifica como uma mulher que unicamente ama mulheres. Considerando também que os manifestos promovem uma doutrina e se caracterizam por possuírem um tom ativista (490), já que desejam oficializar essa doutrina e inseri-la em um debate mais amplo, o texto de Cassandra adota este tom e estrutura na medida que promove a sexualidade de Flávia como natural e até utópica.

Este caráter utópico se concentra, porém, em um tipo específico de mulher que é representado por Flávia. Trata-se da lésbica que jamais teve interesse ou relacionamentos com homens e que tem vantagens socioeconômicas, que muitas outras mulheres no Brasil não tinham e ainda não têm. Dentro do contexto brasileiro de repressão e moralismo de 1980, o romance é transgressivo e até iconoclasta com respeito à sexualidade infantil lésbica, mas quando discute a sexualidade da lésbica adulta não indica que as vantagens socioeconômicas que ela tem —aliás desde a infância — correspondem a hierarquias sociais. Nesse sentido, a ficção cassandriana somente representa uma pequena camada da sociedade.

Ainda com privilégios físicos, econômicos e sociais, devo salientar que Flávia não está pronta para formar comunidade. Ela busca cumprir seus desejos, ao passo que se protege da discriminação que existe em sua sociedade já que não se assume como lésbica publicamente. Deste modo, o romance é menos utópico porque reflete o Brasil que ainda não se libertou completamente da opressão e das ideologias discriminatórias e ainda se encontra em uma posição vulnerável. No começo da década de 80 não era possível para as mulheres, nem mesmo para aquelas com mais privilégios como Flávia, assumirem-se publicamente e serem 
aceitas de forma genuína na sociedade como mulheres que amam somente mulheres.

\section{Obras citadas}

Barbero, Graciela Haydée. Homossexualidade e perversão na psicanálise: uma resposta aos Gay \& Lesbian Studies. Casa do Psicólogo, 2005.

Butler, Judith. Gender Trouble: Feminism and the Subversion of Identity. 1990. Routledge, 2006.

Cuddon, J.A. The Penguin Dictionary of Literary Terms and Literary Theory. 4th ed. Penguin, 1998.

De Lauretis, Teresa. The Practice of Love: Lesbian Sexuality and Perverse Desire. Indiana UP, 1994.

Ellis, Havelock. Psychology of Sex. Vol II: Sexual Inversion. CreateSpace, 2015.

English, Elizabeth. "Part I Fantasy." Lesbian Modernism: Censorship, Sexuality and Genre Fiction. Edinburgh UP, 2015, pp. 25-30.

Facco, Lúcia e Maria Isabel de Castro Lima. "Protagonistas lésbicas: a escrita de Cassandra Rios sob a censura dos anos de chumbo." Labrys, vol. 6, 2004, www.labrys.net.br/labrys6/lesb/bau.htm.

Farwell, Marilyn R. "When is a Lesbian Narrative a Lesbian Narrative?" Heterosexual Plots and Lesbian Narratives. New York UP, 1996, pp. 1-25.

Ferreira-Pinto, Cristina. Gender, Discourse, and Desire in Twentieth-Century Brazilian Women's Literature. Purdue UP, 2004.

Foster, David William. Gay and Lesbian Themes in Latin American Writing. U of Texas P, 1991.

Groneman, Carol. "Nymphomania: The Historical Construction of Female Sexuality.” Signs, vol. 19, no. 2, 1994, pp. 337-67.

Hist, Hilda. O caderno rosa de Lori Lamby. Globo, 2014.

Korich, Hanna, realizador. Cassandra Rios: a safo de perdizes. 2013.

Londero, Rodolfo Rorato. Pornografia e censura: Adelaide Carraro, Cassandra Rios e o sistema literário brasileiro nos anos 1970. Eduel, 2016.

Oosterhuis, Harry. Stepchildren of Nature: Krafft-Ebing, Psychiatry, and the Making of Sexual Identity. U of Chicago P, 2000.

Paim, Mariana Souza. A noite tem mais luzes: considerações sobre a representação do desejo lésbico no romance de Cassandra Rios. 2014, U 
Estadual de Feira de Santana, PhD dissertação.

Piovezan, Adriane. Amor romântico x deleite dos sentidos: Cassandra Rios e a identidade homoerótica feminina na literatura (1948-72). 2005, U Federal do Paraná, $\mathrm{PhD}$ dissertação.

—. "Sou uma lésbica! A estética provocante da escritora Cassandra Rios, pioneira da literatura homoerótica no Brasil." Revista de História da Biblioteca Nacional, vol. 31, 2008, pp. 72-77. WayBackMachine.

-, e Antonio Fontoura, Jr. "Corpos censurados: moralismo no período da ditadura civil-militar e a literatura de Cassandra Rios." Anais do VII congresso internacional de história 6 a 9 de outubro de 2015, Maringá, 2015, pp. 2407-17.

Reimão, Sandra. Repressão e resistência: censura a livros na ditadura militar. 2011, U de São Paulo, Tese de livre docência.

Rich, Adrienne. "Compulsory Heterosexuality and Lesbian Existence." Journal of Women's History, vol. 15, no. 3, 2003, pp. 11-48.

Rios, Cassandra. Eu sou uma lésbica. 1980. Azougue, 2006.

—. Prólogo. Mutreta. Mundo Musical, 1974, pp. 5-12.

Roudinesco, Elisabeth. "Psicanálise e homossexualidade.” Entrevista a François Pommier. Em defesa da psicanálise: ensaios e entrevistas. Edição de Marco Antonio Coutinho Jorge, traduzido por André Telles. Zahar, 2010, pp. 4672 .

Rubin, Gayle. "Thinking Sex: Notes for a Radical Theory of the Politics of Sexuality.” 1984. Deviations: A Gayle Rubin Reader. Duke UP, 2011, pp. 137-81.

Rupp, Leila. "Introduction." Sapphistries: A Global History of Love between Women. New York UP, 2009, pp. 1-9.

Santos, Rick. "Cassandra Rios e o surgimento da literatura gay e lésbica no Brasil." Gênero, vol. 4, no. 1, 2003, pp. 17-31.

- . "O mito maldito: por uma leitura queer do discurso de Cassandra Rios." Mulheres más: percepção e representações da mulher transgressora no mundo luso-hispânico, edição de Ana Maria da Costa Toscano, U Fernando Pessoa, 2004, pp. 255-68.

Silva, Deonísio da. Nos bastidores da censura: sexualidade, literatura e repressão pós 64. Estação Liberdade, 1989.

Stenson, Linnea A. "Literary Images." Encyclopedia of Lesbian and Gay 
Histories and Cultures. Taylor \& Francis, 2000, pp. 474-76.

Sullivan, Rebecca, and Alan McKee. "Introduction." Pornography: Structures, Agency and Performance. Polity, 2015, pp. 11-22.

Theanglerfish. "Lesbian Star Rankings." Feministing, feministing.com/2008 /12/12/lesbian_star_rankings/.

Weeks, Jeffrey. The Languages of Sexuality. Routledge, 2011.

Williams, Linda. "Porn Studies: Proliferating Pornographies On/Scene: An Introduction." Porn Studies, edited by Linda Williams. Duke UP, 2004, pp. $1-23$.

Zimmerman, Bonnie. The Safe Sea of Women: Lesbian Fiction, 1969-1989. Beacon, 1990. 